\title{
Research on Pressure Relief Hole Parameters Based on Abutment Pressure Distribution Pattern
}

\author{
Jian Hao, ${ }^{1}$ Hua Bian $\mathbb{D}^{1},{ }^{1}$ Yongkui Shi, ${ }^{1}$ Anfa Chen $\mathbb{D}^{1},{ }^{1}$ Jiankang Liu, ${ }^{1}$ Peizhe Zhang, \\ Linjun Peng, ${ }^{2}$ and Jianquan Tang ${ }^{1}$ \\ ${ }^{1}$ Mine Disaster Prevention and Control-Ministry of State Key Laboratory Breeding Base, \\ Shandong University of Science and Technology, Qingdao, China \\ ${ }^{2}$ School of Civil Engineering and Architecture, Dalian University, Dalian, China
}

Correspondence should be addressed to Hua Bian; bh199512@163.com and Anfa Chen; anfa108308@163.com

Received 10 September 2021; Accepted 21 October 2021; Published 29 October 2021

Academic Editor: Xiao Wang

Copyright $(92021$ Jian Hao et al. This is an open access article distributed under the Creative Commons Attribution License, which permits unrestricted use, distribution, and reproduction in any medium, provided the original work is properly cited.

Borehole pressure relief technology is an effective way to reduce the elastic energy in the surrounding rock of deep roadways, thereby reducing the risk of regional rock bursts. To avoid large deformation of the roadway caused by pressure relief holes with large diameters and insufficient pressure relief with small pore diameters, this study proposes precise pressure relief holes with nonequal diameters in order to achieve strong pressure relief with minimal disturbance based on the abutment pressure distribution pattern. To verify the pressure relief effect of the nonequal diameter holes, numerical simulations were performed in FLAC3D. This study investigated stress field, deformation laws, and plastic failure zone of roadway surrounding rock with $100 \mathrm{~mm}$ pressure relief holes, nonequal diameter precision pressure relief hole $(100 \mathrm{~mm}+300 \mathrm{~mm})$, and $300 \mathrm{~mm}$ pressure relief holes. The simulation results show that, as the diameter of the pressure relief hole increases, the coupling effect of evenly spaced adjacent pressure relief holes is strengthened, thus improving the pressure relief efficiency. When pressure relief holes of nonequal diameter are adopted, the stress environment of the surrounding rock is clearly improved compared to $100 \mathrm{~mm}$ pressure relief holes, and the plastic failure range increased by 2-3 times. The roof-to-floor convergence with nonequal diameter is $30.8 \%$ that of $300 \mathrm{~mm}$ pressure relief holes and $41 \%$ that of $100 \mathrm{~mm}$ pressure relief holes. Furthermore, the rib displacement is $30.4 \%$ and $46.9 \%$ that of $300 \mathrm{~mm}$ and $100 \mathrm{~mm}$ pressure relief holes, respectively. Thus, precise pressure relief holes with nonequal diameter provide both strong pressure relief associated with large diameter holes and small disturbance of small diameter of small holes. This study provides a reference for precise pressure relief application with pressure relief holes.

\section{Introduction}

Deep mining fundamentally changes the behavior and engineering responses of coal and rock masses due to the action of high ground stress, high ground temperature, high osmotic pressure, and strong time effect for a long time [1-3]. Nonlinear large deformation characteristics and poor support and maintenance effects are observed after roadway excavation. Often, repeated repairs cannot meet mine safety requirements, which seriously affect the efficiency and safety of deep coal [4-6].

A large number of studies have been carried out to improve deep roadway stability, indicating that the surrounding rock stress, mechanical properties, and support strength are the main factors affecting roadway stability. However, it is difficult to control the large deformation of deep roadways by simply improving surrounding rock properties and support strength. Reducing stress in the surrounding rock is an effective way to maintain the stability of this kind of roadway and can be mainly divided into regional prevention or local relief [7-9]. Local relief measures include coal seam unloading blasting, borehole pressure relief, and roof breaking blasting [10-12]. Owing to the sample and convenient construction process and minimal engineering requirements, borehole pressure relief has been widely used to prevent rock burst. 
To date, several achievements have been made in drilling pressure relief for surrounding rock control. The former Soviet Union scholar Reyes et al. showed through experiments that when the hole diameter is $300 \mathrm{~mm}$ and the hole spacing is $1.5-2 \mathrm{~m}$, a good pressure relief effect can be achieved. If the hole diameter is larger than $3 \mathrm{~m}$, the pressure relief effect will be reduced, and a calculation formula for the radius of the fracture zone around a single borehole is proposed [13]. Long Misharov believes that the effect of coal pressure relief close to roadway excavation near roadway working face is the best. When the ratio of coal width to borehole diameter is $0.8-1.0$, it can ensure that the bending strain of rock stratum occurs in the failure space, and the resistance of the coal body is constant. At this time, the best depth of drilling is $10 \mathrm{~m}$ [12]. Zhu et al. [14] proposed an energy dissipation theory and deduced a quantitative method for determining antiblowout drilling parameters based on an energy dissipation index. Jia et al. [15] experimentally studied the effect of various physical parameters, such as diameter, spacing, and depth, on strength and failure patterns of rock specimens in the laboratory. The experimental results were combined with numerical calculations and were used to investigate the number and propagation pattern of cracks in rock specimens under different parameters. Wang et al. [5] experimentally determined the strength parameters and strength attenuation laws of surrounding rock, then studied the effect of pressure relief drilling parameters on stress transfer, and proposed a method for determining the pressure relief drilling parameters. Liu et al. [16] used numerical simulations to analyze damage to the surrounding rock structure and high stress transfer caused by different arrangements of boreholes. Lan et al. [17] simulated and analyzed the effect of borehole diameter, borehole spacing, and coal stress on pressure relief [18]. Both Ma et al. [19] and Song et al. [20] studied the combined support mechanism of combined support of roadway pressure relief holes and bolts.

To date, research on pressure relief holes in mining has mainly focused on the influence of different apertures and hole spacing of equal diameter pressure relief holes on pressure relief. However, if the borehole diameter is too small and the hole spacing is too large, the expected pressure relief effect is not achieved whereas if the aperture is too large and the spacing is too small, instability and failure of roadway surrounding rock will eventually occur. Therefore, this study proposes a precise pressure relief holes with nonequal diameters based on the distribution pattern of abutment pressure to achieve the desired effects of small disturbance and precise and strong pressure relief in surrounding rock of the roadway. The proposed pressure relief hole provides a reference for application of precise pressure relief with pressure relief hole.

\section{Pressure Relief Mechanism of Borehole in High-Stress Roadway}

High pressure in deep roadway surrounding rock is relieved by drilling holes, which releases energy and transfers the peak stress into deeper rock, thereby reducing the stress concentration degree in the coal seam and improving the stress environment of the deep roadway. In addition, drilling changes the physical and mechanical bearing characteristics of the coal seam and reduces both the brittleness and the ability of the coal seam to store elastic energy, thereby reducing the possibility of local stress concentrations in the roadway surrounding rock [16].

Indexes to directly evaluate the pressure relief effect of pressure relief holes include roadway stress transfer effect and surrounding rock deformation control effect. Due to large differences in the stress increase caused by the roadway under different conditions and to simplify the analysis, stress peak in stress increase area, which is an important eigenvalue, is used to characterize high stress around the roadway. As shown in Figure 1, the peak value of vertical stress $\sigma_{p}$ and its position $L\left(\sigma_{p}^{\prime}\right)$ in the surrounding rock of the roadway without boreholes are known for the test roadway. According to the variation of the stress peak $\sigma_{p}$ generated in the roadway under different drilling parameters, at position $L\left(\sigma_{p}^{\prime}\right)$, with original stress peak position $L\left(\sigma_{p}^{\prime}\right)$, the stress transfer around the roadway was comprehensively evaluated [16].

A stress analysis of the coal unit near the borehole was carried out. Stress is continuous, i.e., the stress is equal, at the boundary of elasticity and plasticity. The stress distribution around a pressure relief hole and the radius of plastic zone $R$ can be calculated as follows $[14,16,18]$ :

$$
\left\{\begin{array}{l}
\sigma_{r}=q \times\left(1-\frac{r^{2}}{d^{2}}\right) \\
\sigma_{\theta}=q \times\left(1+\frac{r^{2}}{d^{2}}\right) \\
\tau_{r \theta}=0
\end{array}\right.
$$

where $\sigma_{r}$ is the radial stress, $\mathrm{MPa}, \sigma_{\theta}$ is the tangential stress, $\mathrm{MPa}, \tau_{r \theta}$ is the shearing stress, $\mathrm{MPa}, q$ is the original rock with no borehole, $\mathrm{MPa}, r$ is the radius of pressure relief hole, $m, d$ is the distance between the element and the center of the borehole, $\mathrm{m}, \mathrm{c}$ is the cohesive force of coal, $\mathrm{MPa}$, and $\varphi$ is the internal friction angle of coal, .

According to equations (1) and (2), after the borehole is arranged in the coal wall, tangential stress around the borehole will generate a certain stress concentration with stress concentration coefficient in the range $2-3$, and the radial stress around the borehole will be zero, i.e., the wall is in the unidirectional compression state. The radius of the relief zone of the relief hole is related to the vertical stress $q$ of the coal mass, radius of the pressure relief hole $r$, cohesion force of coal $c$, and internal friction angle $\varphi$.

When working conditions are known, the size of the relief area generated by the pressure relief hole will be proportional to the pore size of the pressure relief hole. Therefore, borehole diameter is one of the most important factors affecting the pressure relief effect of the borehole and is particularly important in reasonably selecting the borehole diameter. For 


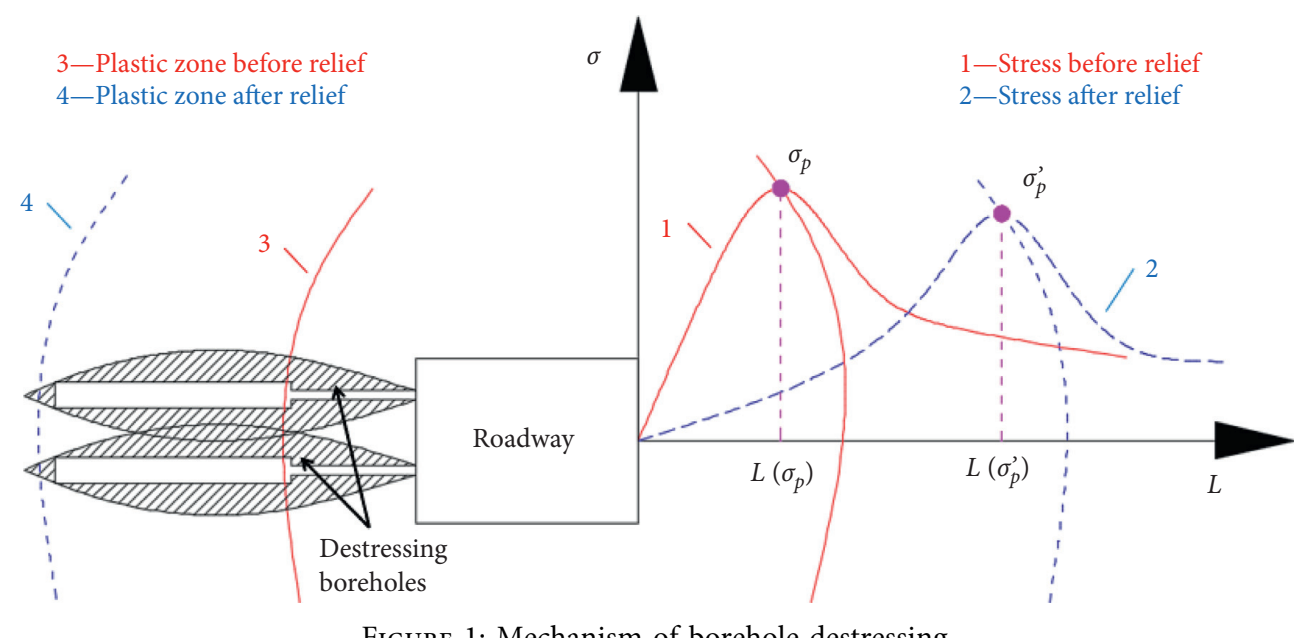

Figure 1: Mechanism of borehole destressing.

traditional equal diameter pressure relief holes, if the diameter of the pressure relief hole is too small, the expected pressure relief effect cannot be achieved. If the aperture is too large, the stability of surrounding rock will be seriously affected [21].

To address the shortcomings of traditional equal diameter pressure relief holes, in this study, a nonequal diameter precision pressure relief hole based on abutment pressure distribution characteristics is proposed. In the process of mining the working face, abutment pressure distributed on the surrounding coal wall can be divided into two areas, an external stress field under higher stress than the original rock and an internal stress field in a lower stress than the original rock [22].

The distribution of the internal stress field can be calculated as

$$
S_{0}=\sqrt{\frac{L C_{0} S_{p} \sum_{1}^{n} m_{i}}{\left(L+C_{0}\right) k H}}
$$

where $S_{0}$ is the range of internal stress field, $m, S_{P}$ is the distance between the position of peak support pressure and the coal wall, $m, m_{i}$ is thickness of basic top rock beam, $m, k$ is the stress concentration factor, $H$ is the mining depth, $m$, and $C_{0}$ is the basic top periodic weighting step, $m$.

Based on the distribution pattern of abutment pressure, a nonequal diameter precise pressure relief hole structure is proposed, using small diameter pressure relief holes in the internal stress field and large diameter pressure relief holes in the external stress field. With continuous changes in abutment pressure, the distribution of large and small boreholes can be adjusted in real time to achieve effective and accurate pressure relief.

\section{Numerical Simulation of Drilling Pressure Relief}

3.1. Numerical Model. The geological conditions of Zaoquan Coal Mine were taken as an example and a numerical model was established in FLAC3D. The length, width, and height of the numerical model were 201,64 , and $36 \mathrm{~m}$, respectively. The excavation roadway section length was $5 \mathrm{~m}$ and the height was $3.9 \mathrm{~m}$. The calculation model is established by the hexahedral block grid (brick) and the cylindrical tunnel peripheral gradient radial grid (radcylinder), and the strain softening is selected for the constitutive relationship. To eliminate boundary effects, a protective coal pillar was set at a distance of $50 \mathrm{~m}$ from the working face to the model boundary. The model was divided into five layers, and the rock parameters of each coal layer are listed in Table 1 $[17,19,20]$.

A vertical constraint was adopted at the bottom of the model and a horizontal constraint at the side and no constraint on the top surface. The distance from the ground was about $667 \mathrm{~m}$. Taking the bulk density of the overlying strata as $25 \mathrm{kN} / \mathrm{m}^{2}$, the stress of the overlying strata was set to 16.69 MPa and applied to the top of the model. The numerical calculation model is illustrated in Figure 2. The model comprised 889,856 units and 868,996 nodes.

3.2. Numerical Simulation Scheme. After the initial model was established, boundary conditions were set and the upper load was applied. The first balancing calculation was performed and once equilibrium was reached; roadway excavation was simulated. At the end of the roadway excavation, a second balancing calculation was carried out and once equilibrium was reached again, a pressure relief hole was added [23-25]. The FLAC3D built-in FISH language was used for cyclic coal seam excavation of the mining face. Each excavation was $10 \mathrm{~m}$ and was performed after each balancing calculation. The layout of the pressure relief holes is shown in Figure 3. To study the pressure relief effect of nonequal diameter precise pressure relief holes, three simulation schemes were used in the numerical simulation: pressure relief holes with a diameter of (1) $100 \mathrm{~mm}$, (2) $100+300 \mathrm{~mm}$, and (3) $300 \mathrm{~mm}$ and a depth of $15 \mathrm{~m}$. The row spacing between the relief holes is shown in Figure 4 .

\section{Analysis of Numerical Simulation Results}

To study the pressure relief effect of nonequal diameter precise pressure relief holes, the vertical stress distribution, deformation law, and plastic zone distribution pattern of the 
TABLE 1: Rock mechanical properties of each rock stratum.

\begin{tabular}{|c|c|c|c|c|c|c|}
\hline $\begin{array}{l}\text { Name of rock } \\
\text { stratum }\end{array}$ & $\begin{array}{l}\text { Strata thickness } \\
(\mathrm{m})\end{array}$ & $\begin{array}{l}\text { Bulk modulus } \\
\quad(\mathrm{GPa})\end{array}$ & $\begin{array}{l}\text { Shear modulus } \\
(\mathrm{GPa})\end{array}$ & $\begin{array}{c}\text { Cohesion } \\
(\mathrm{MPa})\end{array}$ & $\begin{array}{c}\text { Internal friction } \\
\text { angle }^{\circ} \text { ) }\end{array}$ & Density $\left(\mathrm{kg} \cdot \mathrm{m}^{-3}\right)$ \\
\hline Basic roof & 11 & 6 & 4.13 & 3.2 & 36 & 2700 \\
\hline Immediate roof & 7.5 & 3.77 & 2.48 & 2.3 & 27 & 2400 \\
\hline Coal seam & 3 & 3 & 1.89 & 1.4 & 26 & 1700 \\
\hline Immediate bottom & 3.5 & 4.88 & 3.36 & 2.1 & 32 & 2000 \\
\hline Basic bottom & 14 & 5.77 & 3.98 & 2.5 & 35 & 2600 \\
\hline
\end{tabular}

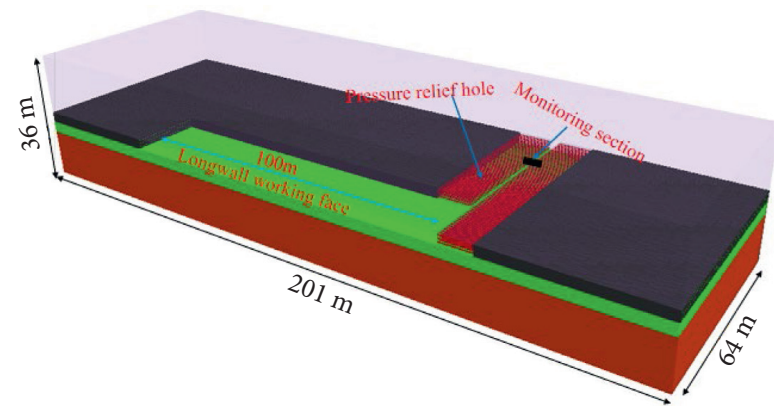

Figure 2: Numerical calculation model.

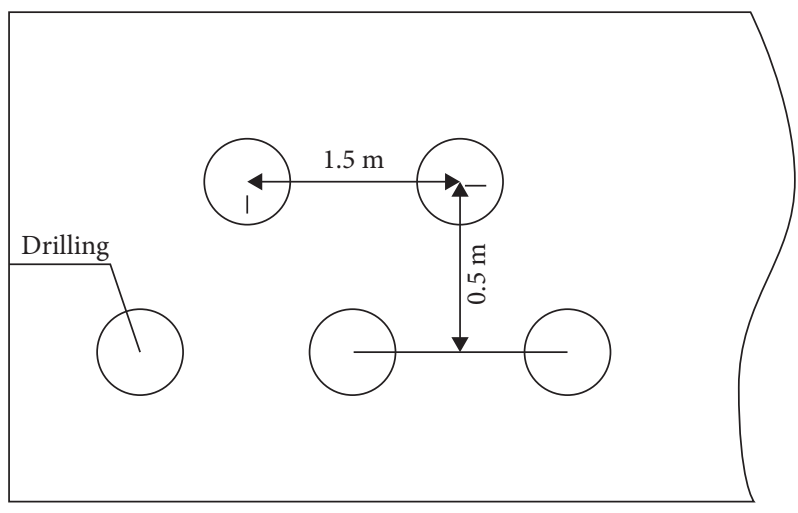

FIgURE 3: Layout of pressure relief hole.

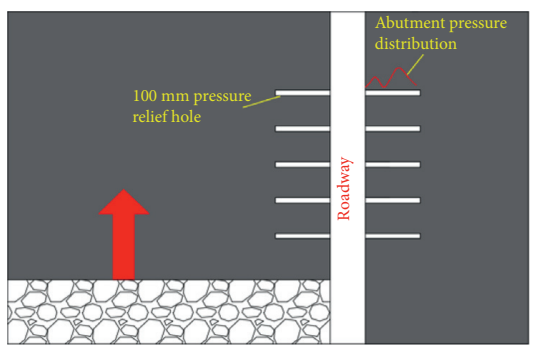

(a)

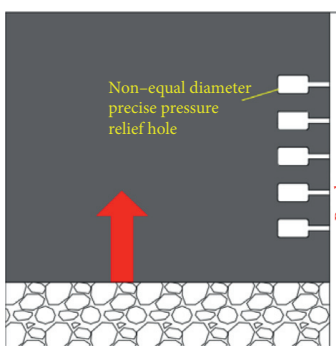

(b)
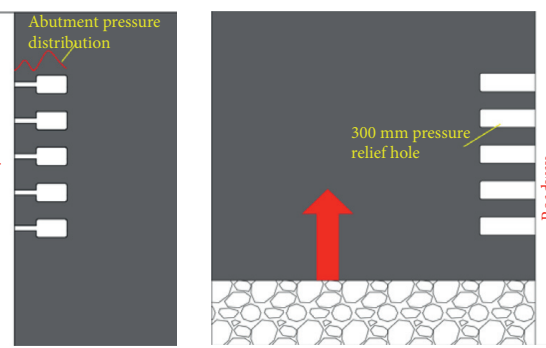

(c)

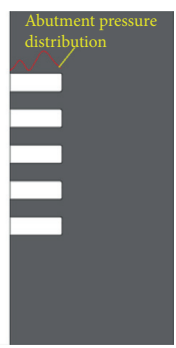

Figure 4: Schematic diagram of pressure relief hole layout. (a) $100 \mathrm{~mm}$ pressure relief hole. (b) Nonequal diameter precision pressure relief hole. (c) $300 \mathrm{~mm}$ pressure relief hole.

roadway surrounding rock under three schemes with $100 \mathrm{~mm}$ pressure relief holes, nonequal diameter precise pressure relief holes $(100+300 \mathrm{~mm})$, and $300 \mathrm{~mm}$ pressure relief holes were analyzed.
4.1. Vertical Pressure Distribution. Since stress is mainly concentrated in the vertical direction in the process of working face stopping, variation of vertical stress under different relief hole schemes was analyzed. The vertical stress distribution 
nephogram near the borehole from the coal side to the deep part of the surrounding rock is shown in Figure 5. To eliminate the boundary effect, a section with $y=32 \mathrm{~m}$ (corresponding to a roadway length of $64 \mathrm{~m}$ ) was selected.

Figure 5(a) shows that the pressure relief ring of the $100 \mathrm{~mm}$ pressure relief hole does not completely cover the surrounding rock between the boreholes, and there are stress concentrations between the pressure relief holes, with the peak stress as $21.8 \mathrm{MPa}$. Figures 5(b) and 5(c) show that the pressure ring of the pressure relief hole completely covers the surrounding rock between adjacent boreholes in the other two schemes, and the corresponding force is concentrated along depth and transferred to the end of the pressure relief hole, which effectively adjusts the stress environment of the roadway. When the boreholes are evenly spaced, increasing the borehole diameter can effectively improve the stress relief effect.

At the same depth of surrounding rock (less than the length of the pressure relief hole), surrounding rock sections perpendicular to the axis of the relief holes were considered. By analyzing the vertical stress distribution of sections at different depths, the variation in the pressure relief effect with drilling depth was studied. The vertical stress distribution of sections at different depths $(2,4$, and $6 \mathrm{~m})$ along the axis of the pressure relief holes is shown in Figures 6-8.

As shown in Figures 6-8, at the same depth from the coal rib, as the pore size of the pressure relief hole increases, the pressure relief effect gradually increases. Compared to the $100 \mathrm{~mm}$ pressure relief holes, the vertical stress of the nonuniform diameter pressure relief holes at depths of 2, 4, and $6 \mathrm{~m}$ is reduced by $14 \%, 23.4 \%$, and $70.2 \%$, respectively. Compared to $100 \mathrm{~mm}$ pressure relief holes, the vertical stress of the $300 \mathrm{~mm}$ pressure relief hole at of 2,4 , and $6 \mathrm{~m}$ decreased by $50.7 \%, 57.3 \%$, and $74.5 \%$, respectively.

4.2. Plastic Failure Characteristics of Surrounding Rock. Since the unloading effect of the pressure relief holes is usually characterized by a plastic zone, of different schemes (100, $100+300$, and $300 \mathrm{~mm}$ pressure relief hole) were studied. The distribution of the plastic zone along different depths $(4,6$, and $8 \mathrm{~m}$ ) along the axis of relief hole axis is shown in Figures 9-11.

As shown in Figures 9-11, the size of the plastic zone gradually increases as the pressure relief hole diameter increases. Under the influence of lateral abutment pressure, the distribution of the plastic zone at section $4 \mathrm{~m}$ away from the roadway wall is basically the same. With increasing depth, the sizes of plastic zones with nonequal diameter pressure relief holes and $300 \mathrm{~mm}$ pressure relief holes are obviously larger than that with $100 \mathrm{~mm}$ pressure relief holes, about 2-3 times larger, and the sizes of the plastic zones with nonequal diameter pressure relief holes and $300 \mathrm{~mm}$ pressure relief hole are basically the same.

\subsection{Deformation Pattern of Roadway Surrounding Rock}

4.3.1. Deformation Characteristics of Roadway Roof and Floor. To study the pressure relief effect of nonequal diameter precise pressure relief holes, the approaching amount of roof and floor in the working face was monitored under conditions with $100 \mathrm{~mm}$ pressure relief holes, nonequal diameter precise pressure relief holes, and $300 \mathrm{~mm}$ pressure relief holes. Figure 12 shows the approaching curve diagrams of roof-to-floor convergence.

As the distance from the working face to the monitoring point decreases, the roof-to-floor convergence increases, as illustrated in Figure 12. In the $300 \mathrm{~mm}$ relief hole scheme, the roof-to-floor convergence, represented as vertical displacement, is $696.7 \mathrm{~mm}$, which is the largest. In the $100 \mathrm{~mm}$ relief hole scheme, the roof-to-floor convergence is $520.2 \mathrm{~mm}$ and the roof-to-floor convergence of the nonequal diameter precise pressure relief hole scheme is the smallest, with a vertical displacement of $213.8 \mathrm{~mm}$. Under the condition of nonequal diameter pressure relief holes, the roofto-floor convergence is $30.8 \%$ and $41 \%$ of the $300 \mathrm{~mm}$ and $100 \mathrm{~mm}$ schemes, respectively.

\subsubsection{Deformation Characteristics of Two Ribs of Roadway.} To study the pressure relief effect of nonequal diameter precise pressure relief holes, the approaching amount of two sides along with advancing roof of the working face is monitored under the schemes with $100 \mathrm{~mm}$ pressure relief holes, nonequal diameter precise pressure relief holes, and $300 \mathrm{~mm}$ pressure relief holes. Figure 13 shows the curves of the approaching amount of the two sides.

With decreasing distance from working face to the monitoring point, the formation of the surrounding rock continuously increases, as shown in Figure 13. With $300 \mathrm{~mm}$ pressure relief holes, the displacement of the two ribs is largest at $932.3 \mathrm{~mm}$. The displacement with $100 \mathrm{~mm}$ pressure relief holes is $604.2 \mathrm{~mm}$, and with the nonequal diameter precise pressure relief hole scheme, it is $283.3 \mathrm{~mm}$, which is the smallest displacement. Under the nonequal diameter pressure relief hole condition, the displacements of the roof and floor plate are $30.4 \%$ and $46.9 \%$ of the $300 \mathrm{~mm}$ and $100 \mathrm{~mm}$ schemes, respectively.

\section{Discussion}

According to the deformation curve of the roadway surrounding rock shown in Figures 12 and 13, when the working face advances to about $20 \mathrm{~m}$ from the monitoring point, the roadway surrounding rock begins to produce more obvious deformation, and the deformation rate becomes larger and larger with back mining of the working face. Under nonequal diameter precise pressure relief hole scheme, deformation of the roadway surrounding rock is smallest; however, the pressure relief effect is similar to that of the $300 \mathrm{~mm}$ pressure relief hole scheme, providing both the strong pressure relief of large diameter pressure relief holes and small disturbance of small diameter pressure relief holes.

The deformation of roadway surrounding rock is mainly affected by the stress environment, rock mechanical properties, and rock structural plane. Equation (2) shows that the plastic failure range of surrounding rock increases with increasing pressure relief hole diameter. Therefore, although 


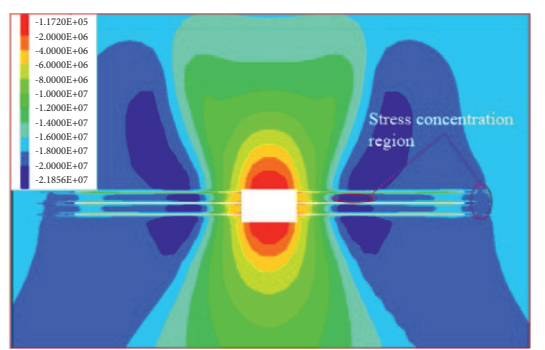

(a)

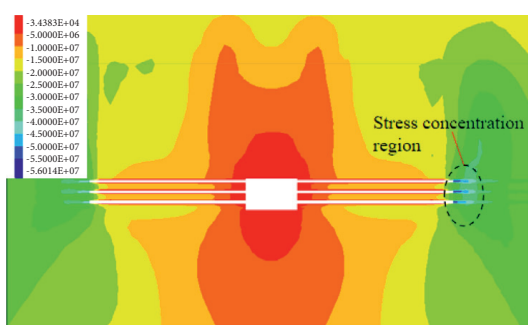

(b)

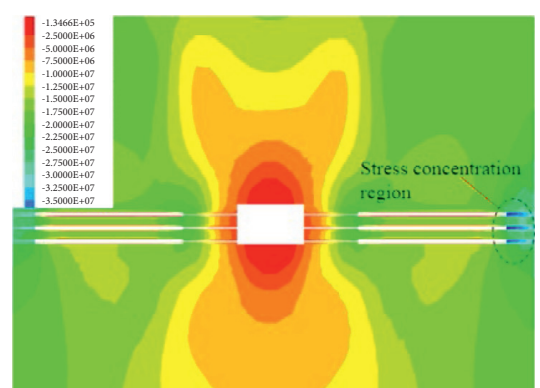

(c)

FIGURE 5: Vertical stress distribution near borehole. (a) $100 \mathrm{~mm}$ pressure relief hole. (b) Nonequal diameter precision pressure relief hole. (c) $300 \mathrm{~mm}$ pressure relief hole.

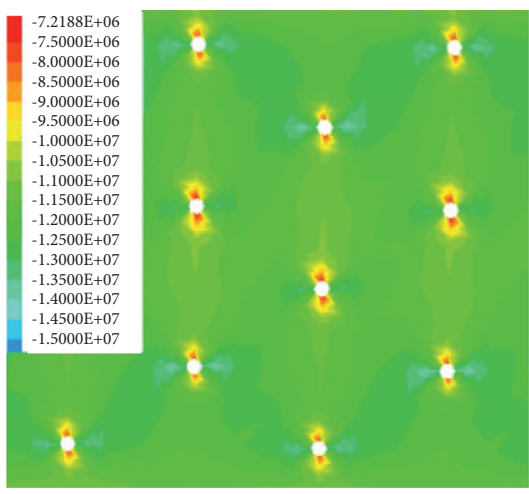

(a)

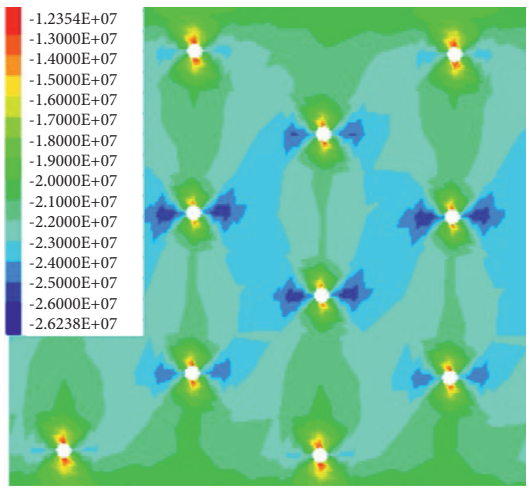

(b)

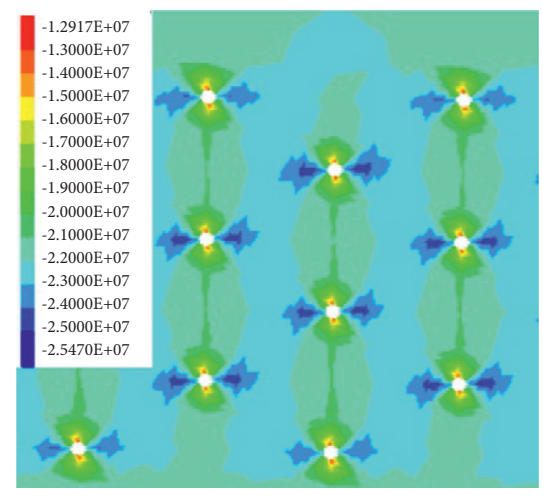

(c)

Figure 6: Vertical stress distribution of $100 \mathrm{~mm}$ pressure relief hole at different depths along the axis direction. (a) $2 \mathrm{~m}$ from the coal rib. (b) $4 \mathrm{~m}$ from the coal rib. (c) $6 \mathrm{~m}$ from the coal rib.

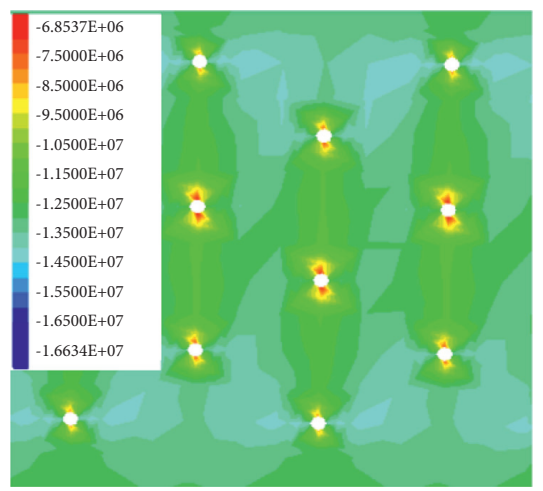

(a)

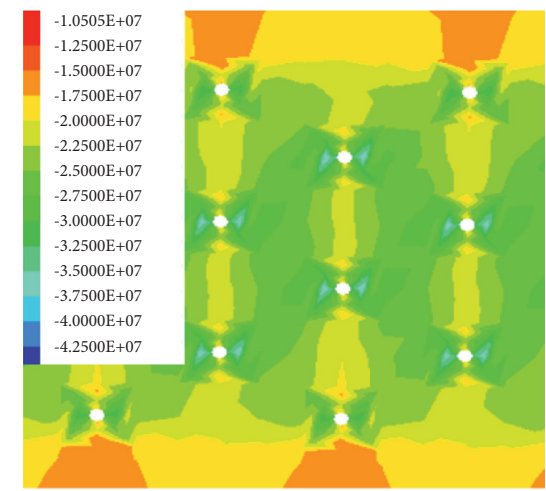

(b)

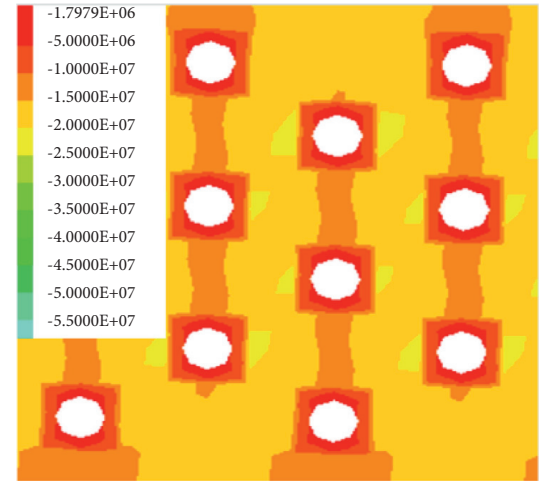

(c)

FiguRE 7: Vertical stress distribution of nonequal diameter pressure relief hole a different depths along the axis. (a) $2 \mathrm{~m}$ from the coal rib. (b) $4 \mathrm{~m}$ from the coal rib. (c) $6 \mathrm{~m}$ from the coal rib.

the $300 \mathrm{~mm}$ pressure relief hole achieves better pressure relief effects, large plastic failure is observed around the borehole, which seriously deteriorates the mechanical properties of surrounding rock and aggravates the deformation of the surrounding rock of the roadway. Owing to the small pore size, the plastic failure zone of $100 \mathrm{~mm}$ pressure relief hole is reduced, thus providing poor pressure relief, and the surrounding rock remains under a high-stress environment.

Based on the distribution pattern of abutment pressure, in the internal stress field near the coal wall, small diameter drilling was adopted for nonequal diameter precise pressure relief hole to reduce the influence of drilling on the mechanical properties of the coal mass. In the external stress 


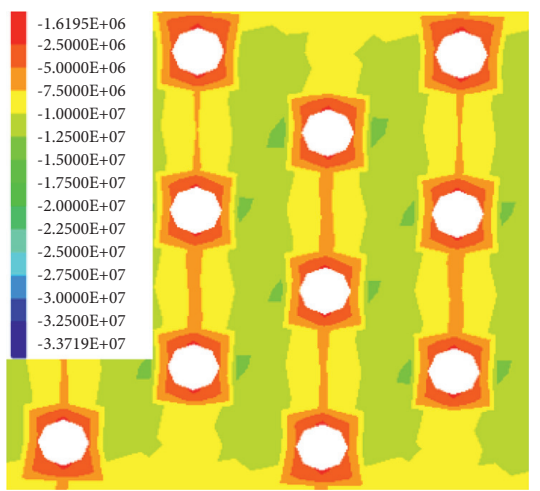

(a)

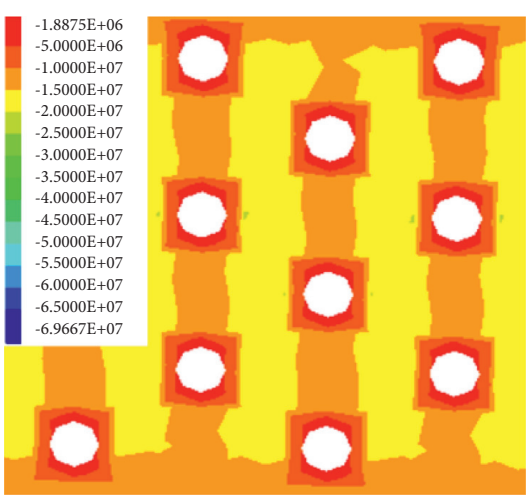

(b)

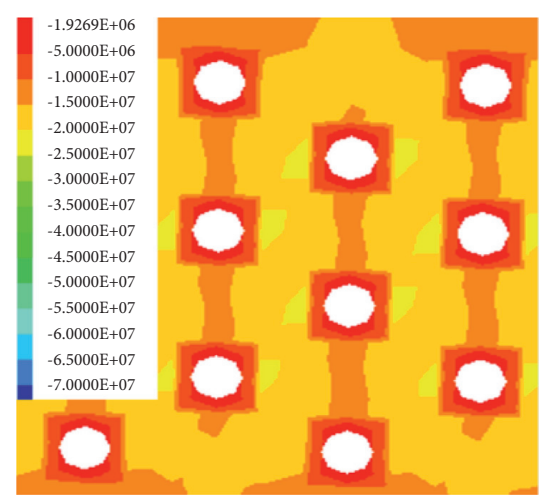

(c)

FiguRE 8: Vertical stress distribution of $300 \mathrm{~mm}$ pressure relief hole in different depths along the axis direction. (a) $2 \mathrm{~m}$ from the coal rib. (b) $4 \mathrm{~m}$ from the coal rib. (c) $6 \mathrm{~m}$ from the coal rib.

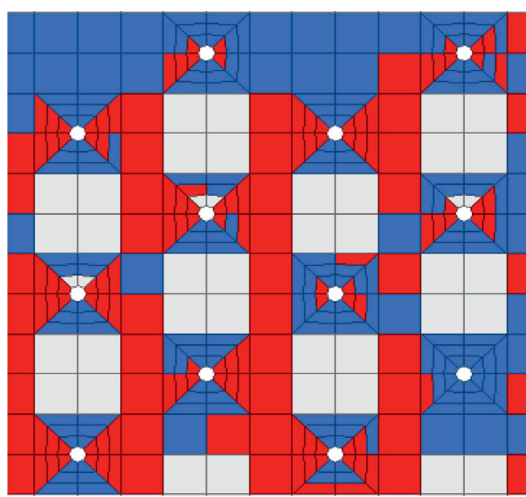

(a)

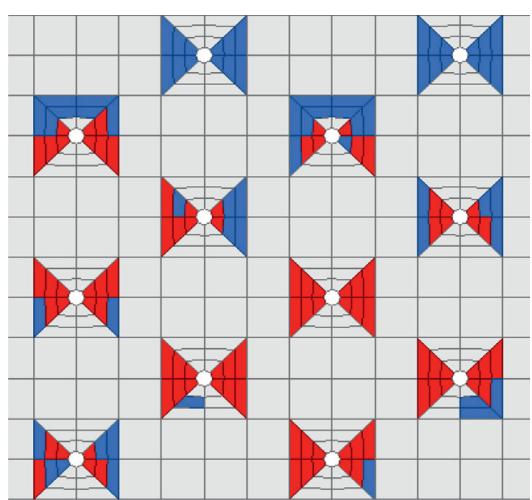

(b)

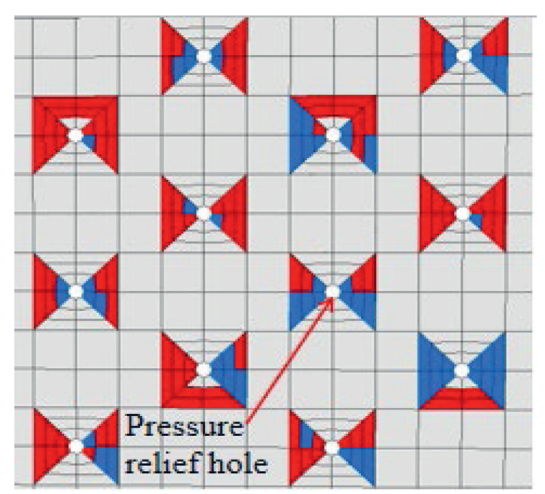

(c)

Figure 9: Distribution law of plastic zone of $100 \mathrm{~mm}$ pressure relief hole. (a) $4 \mathrm{~m}$ from the coal rib. (b) $6 \mathrm{~m}$ from the coal rib. (c) $8 \mathrm{~m}$ from the coal rib.

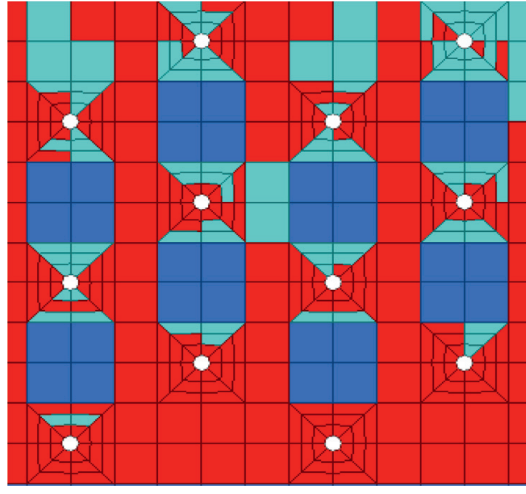

(a)

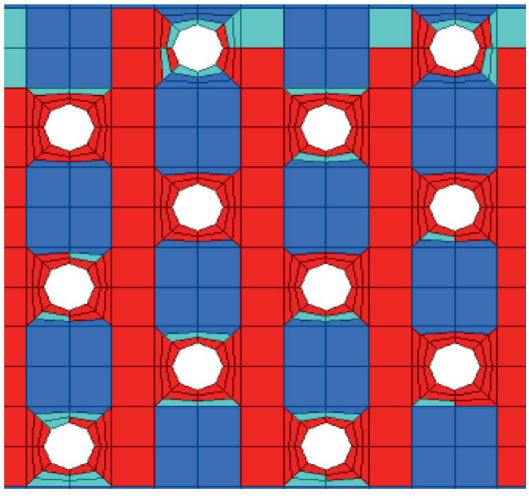

(b)

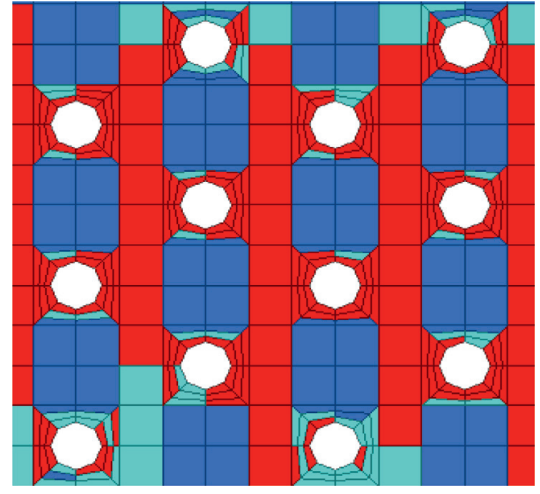

(c)

Figure 10: Distribution law of plastic zone of nonequal diameter precise pressure relief hole. (a) $4 \mathrm{~m}$ from the coal rib. (b) $6 \mathrm{~m}$ from the coal rib. (c) $8 \mathrm{~m}$ from the coal rib.

field which is higher than the original rock stress, adopting large diameter drilling can reduce the effect of the roadway wall on the surrounding rock to the greatest extent. The numerical experiments show that vertical stress is reduced by $14 \%, 23.4 \%$, and $70.2 \%$ with the nonequal diameter pressure relief hole at the depths of 2,4 , and $6 \mathrm{~m}$, respectively, and by $50.7 \%, 57.3 \%$, and $74.5 \%$ with $300 \mathrm{~mm}$ pressure relief hole at depths of 2, 4, and $6 \mathrm{~m}$. Under the 


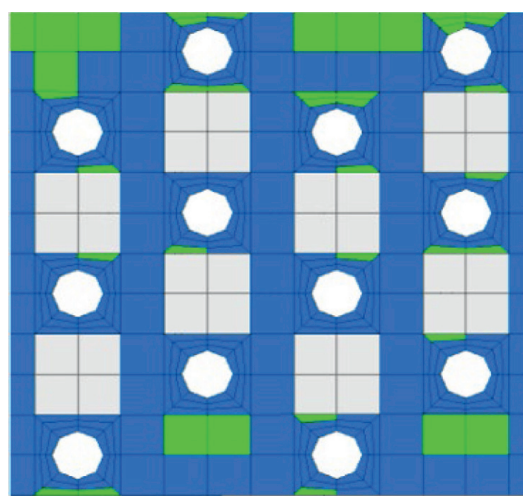

(a)

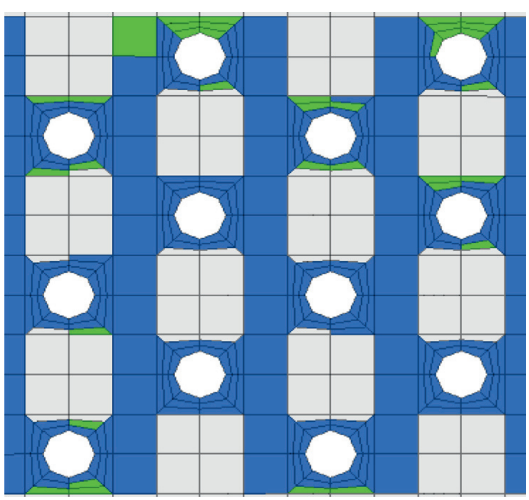

(b)

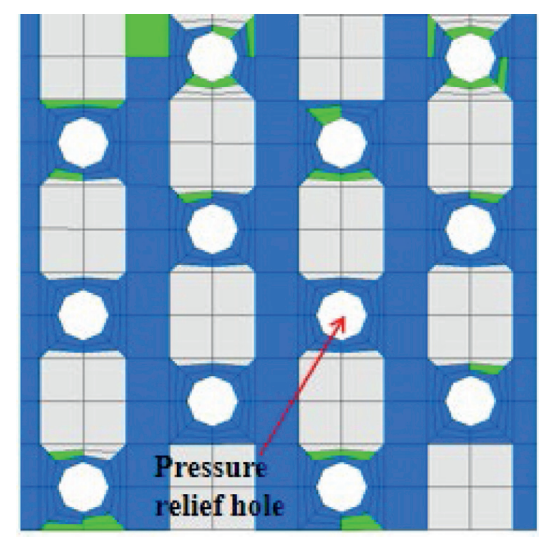

(c)

FIgURe 11: Distribution law of plastic zone of $300 \mathrm{~mm}$ pressure relief hole. (a) $4 \mathrm{~m}$ from the coal rib. (b) $6 \mathrm{~m}$ from the coal rib. (c) $8 \mathrm{~m}$ from the coal rib.

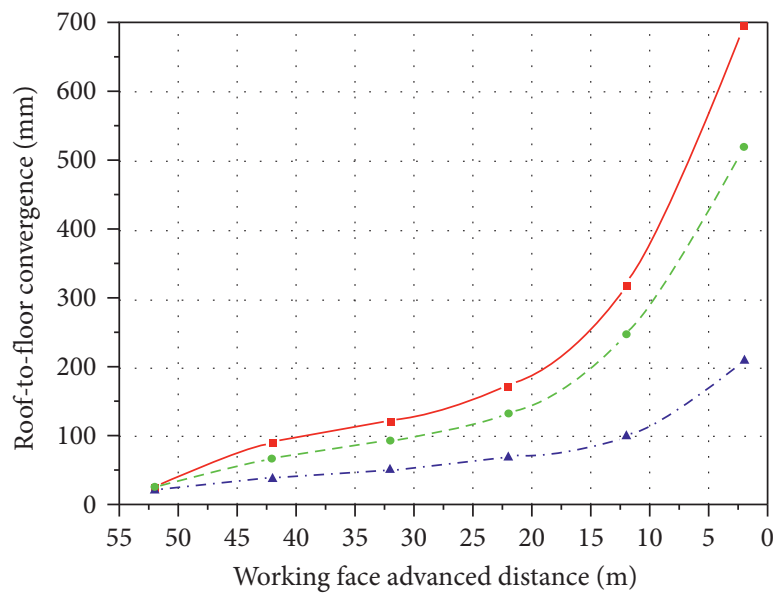

- $-\star$ - Non-equal diameter pressure relief hole

$\rightarrow-300 \mathrm{~mm}$ pressure relief holes

- $-100 \mathrm{~mm}$ pressure relief holes

Figure 12: Roof-to-floor convergence curve.

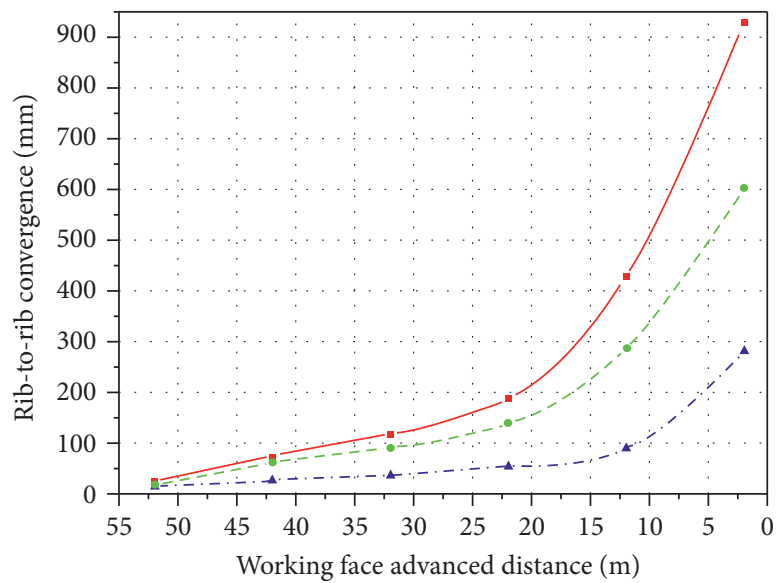

$-\star-$ - Non-equal diameter pressure relief hole

$-300 \mathrm{~mm}$ pressure relief holes

- - $100 \mathrm{~mm}$ pressure relief holes

FIGURE 13: Rib-to-rib convergence curve. 
nonequal diameter pressure relief hole condition, the displacement of the roof and floor is $30.4 \%$ and $46.9 \%$ in $300 \mathrm{~mm}$ and $100 \mathrm{~mm}$ pressure relief holes, respectively, and displacement of the two sides is $30.8 \%$ and $41 \%$ in $300 \mathrm{~mm}$ and $100 \mathrm{~mm}$ pressure relief holes.

In summary, drilling of nonequal diameter precise pressure relief holes in high-stress areas not only reduces the stress concentration but also effectively maintains the stability of roadway surrounding rock. Therefore, methods to precisely and quickly determine the abutment pressure distribution should be studied, and new drilling tools and appropriate reaming devices should be developed to improve the efficiency and accuracy of nonequal diameter pressure relief holes.

\section{Conclusions}

Borehole pressure relief is one of the effective measures for preventing and controlling rock burst. In this study precise pressure relief holes with nonequal diameters were proposed and successfully designed. Existing borehole pressure relief theory and the internal and external stress field theory were used to investigate the effect of pressure relief hole diameter on the pressure relief effect. Based on the numerical simulation results, the main conclusions of this study can be summarized as follows:

(1) The theoretical analysis results showed that when pressure relief holes are evenly spaced, the coupling effect of adjacent pressure relief holes is strengthened with increasing diameter of pressure relief holes increasing, and the pressure relief efficiency is improved. Moreover, the pressure relief effect becomes more obvious.

(2) From the pressure relief effect, the vertical stress at the depths of 2,4 , and $6 \mathrm{~m}$ of the nonequal diameter pressure relief hole is reduced by $14 \%, 23.4 \%$, and $70.2 \%$, respectively, compared with those of the $100 \mathrm{~mm}$ pressure relief hole. The plastic failure range of the nonequal diameter pressure relief holes and $300 \mathrm{~mm}$ pressure relief holes are similar and are 2-3 times greater than that of $100 \mathrm{~mm}$ pressure relief holes, with preferable pressure relief effects.

(3) From the perspective of roadway surrounding rock deformation, the roof-floor convergence with nonequal diameter pressure relief hole is $30.8 \%$ in $300 \mathrm{~mm}$ pressure relief holes, $41 \%$ in $100 \mathrm{~mm}$ holes, the rib convergence is $30.4 \%$ in $300 \mathrm{~mm}$ pressure relief holes, and $46.9 \%$ in $100 \mathrm{~mm}$ pressure relief holes. Thus, the proposed nonequal diameter pressure relief holes can effectively maintain the stability of roadway surrounding rock.

In summary, nonequal diameter precise pressure relief holes exhibit both the strong pressure relief of large diameter pressure relief holes and small disturbance of small diameter pressure relief holes, thus providing more precise pressure relief.

\section{Data Availability}

The data used to support the findings of this study are available from the corresponding author upon request.

\section{Conflicts of Interest}

The authors declare no conflicts of interest.

\section{Acknowledgments}

This study was financially supported by the National Natural Science Foundation of China (Grant no. 51804180 and 52174121).

\section{References}

[1] M. Wang, Y. Si, J. Hu, and H. Deng, "The coordination control technology of pressure relief and its application in deep roadway," Journal of Henan Polytechnic University (Natural Science), vol. 36, no. 5, pp. 9-16, 2017.

[2] M. Wang, X. Y. Wang, and T. Q. Xiao, "Borehole destressing mechanism and determination method of its key parameters in deep roadway," Journal of China Coal Society, vol. 42, no. 5, pp. 1138-1145, 2017.

[3] H. P. Xie, F. Gao, Y. Ju et al., "Quantitative definition and investigation of deep mining," Journal of China Coal Society, vol. 40, no. 1, pp. 1-10, 2015.

[4] M. C. He, "Progress and challenges of soft rock engineering in depth," Journal of China Coal Society, vol. 39, no. 8, pp. 1409-1417, 2014.

[5] M. C. He, H. P. Xie, S. P. Peng, and Y.-D. Jiang, "Study on rock mechanics in deep mining engineering," Chinese Journal of Rock Mechanics and Engineering, vol. 24, no. 16, pp. 28032813, 2005.

[6] Y. Jiang, W. Liu, Y. Zhao et al., "Study on surrounding rock stability of deep mining in kailuan mining group," Chinese Journal of Rock Mechanics and Engineering, vol. 24, no. 11, pp. 1857-1862, 2005.

[7] H. P. Kang, J. H. Wang, and J. Liu, "High pretensioned stress and intensive bolting system and its application in deep roadways," Journal of China Coal Society, vol. 32, no. 12, pp. 1233-1238, 2007.

[8] C. J. Hou, Roadway surrounding rock control, Ph.D. Dissertation, China university of mining and technology press, Xuzhou, China, 2013.

[9] Y. D. Jiang, Y. S. Pan, F. X. Jiang, L.-M. Dou, and Y. Ju, “State of the art review on mechanism and prevention of coal bumps in China," Journal of China Coal Society, vol. 39, no. 2, pp. 205-213, 2014.

[10] B. Ma, Z. Deng, S. Zhao, S. Li, Y. Feng, and Z. Su, "Prevention technology of strong strata behaviors of mining roadway with hard roof and hard coal," Safety In Coal Mines, vol. 48, no. 12, pp. 139-141, 2017.

[11] W. D. Ortlepp and T. R. Stacey, "Rockburst mechanisms in tunnels and shafts," Tunnelling and Underground Space Technology, vol. 9, no. 1, pp. 59-65, 1994.

[12] M. Kiyoo, "Effect of the intermediate principal stress on rock failure," Journal of Geophysical Research, vol. 72, no. 1, pp. 5117-5131, 1967.

[13] O. Reyes and H. H. Einstein, "Failure mechanisms of fractured rock: a fracture coalescence model," Isrm Congress, vol. 1, pp. 334-380, 1991.

[14] S. Zhu, F. Jiang, X. Shi et al., "Energy dissipation index method for determining rockburst prevention drilling parameters," Rock and Soil Mechanics, vol. 36, no. 8, pp. 2270-2276, 2015.

[15] C. Y. Jia, Y. J. Jiang, X. P. Zhang, D. Wang, H. Luan, and C.-S. Wang, "Laboratory and numerical experiments on 
pressure relief mechanism of large -diameter boreholes," Chinese Journal of Geotechnical Engineering, vol. 3, no. 6, pp. 1115-1122, 2017.

[16] H. Liu, Y. He, J. Xu, and L. Han, "Numerical simulation and industrial test of boreholes destressing technology in deep coal tunnel," Journal of China Coal Society, vol. 32, no. 1, pp. 33-37, 2007.

[17] Y. W. Lan, "The study on drillhole pressure relief preventing rockburst in Coal Mine," Dissertation, Liaoning Technical University, Fuxin, China, 2004.

[18] Z. H. Guo, "Borehole destressing mechanism and key parameters determination of roadway in isolated working face," Journal of Taiyuan University of Technology, vol. 51, no. 6, pp. 906-911, 2020.

[19] Z. G. Ma, Y. D. Jiang, Y. W. Li, and Y. M. Yang, "Collaborative control of pressure-released boreholes with U-steel of roadways in ultra-soft coal seam," Journal of China Coal Society, vol. 40, no. 10, pp. 2279-2286, 2015.

[20] X. X. Song, Y. J. Zuo, and X. Wang, "Numerical simulation of pressure-released hole combined support with rock bolt in deep roadway with dynamic disturbance," Journal of Central South University, vol. 45, no. 9, pp. 3158-3165, 2004.

[21] K. Ding, Study on Pressure Relief Mechanism and Engineering Application of Sectional Borehole Enlargement Technology, Shan Dong University and Science and Technology, Qingdao, China, 2016.

[22] Z. Song, Y. Song, Y. Liu, and J. Jiang, "Theory of internal and external stress field and its application in mine pressure control," in Proceedings of the North China Conference on Rock Mechanics and Engineering Application, p. 11, Norman, OK, USA, July 1991.

[23] Y. Gao, Z. Jin, X. Meng, and J. Zhang, "Effects of hole diameter and arrangement on tunneling surfacer relief effect," Coal Technology, vol. 36, no. 1, pp. 138-140, 2017.

[24] W. Jing, X. Hou, H. Xu, and C. Liang, "Design of technical parameters for pressure relief of boreholes based on FLAC simulation," Coal and chemical industry, vol. 37, no. 1, pp. 105-108, 2014.

[25] Y. Zhang, Y. Zhu, and H. Zhang, "Optimization of large diameter pressure relief drilling depth on impact dangerous working face," Modern Mining, vol. 35, no. 8, pp. 199-201, 2019. 